\title{
Contrasting renal functional reserve in very long-term Type I diabetic patients with and without nephropathy
}

\author{
H.Sackmann ${ }^{1}$,T. Tran-Van ${ }^{2}$, I. Tack ${ }^{2}$, H.Hanaire-Broutin ${ }^{1}$, J.-P.Tauber ${ }^{1}$, J.-L. Ader ${ }^{2}$ \\ ${ }^{1}$ Diabetology and Endocrinology Department, Rangueil University Hospital, Toulouse, France \\ ${ }^{2}$ Kidney Clinical Investigation Laboratory and INSERM Unit 388, Rangueil University Hospital, Toulouse, France
}

\section{Abstract}

Aims. This study was to determine whether renal functional reserve (RFR) is present in patients who have suffered long-lasting Type I (insulin-dependent) diabetes mellitus.

Methods. Renal functional reserve was elicited by a 3-h amino acid infusion $\left(4.5 \mathrm{mg} \cdot \mathrm{kg}^{-1} \cdot \mathrm{min}^{-1}\right)$ in 10 patients with nephropathy $(\mathrm{DN}+)$ and 10 patients without nephropathy (DN-) who had lived with diabetes for $24 \pm 3$ and $27 \pm 3$ years, respectively and in 15 healthy control subjects. Renal functional reserve was calculated as the difference between amino acidstimulated and baseline glomerular filtration rates (GFR).

Results. Baseline glomerular filtration rate in $\mathrm{DN}-$ patients $(106 \pm 8)$ and control subjects $(112 \pm 3 \mathrm{ml}$. $\left.\mathrm{min}^{-1} \cdot\left(1.73 \mathrm{~m}^{2}\right)^{-1}\right)$ was significantly higher $(p<0.01)$ than in $\mathrm{DN}+$ patients $\left(79 \pm 7 \mathrm{ml} \cdot \mathrm{min}^{-1} \cdot\left(1.73 \mathrm{~m}^{2}\right)^{-1}\right)$. Renal functional reserve was absent in $\mathrm{DN}+$ pa- tients, whereas it represented $26 \pm 4 \%$ of the baseline in $\mathrm{DN}$ - patients and $23 \pm 2 \%$ in control subjects. Renal vascular resistance decreased statistically significantly during amino acid infusion in $\mathrm{DN}-$ patients and control subjects but not in DN + patients.

Conclusions/hypothesis. These results indicate that very long-term Type I diabetic patients without diabetic nephropathy still have a normal renal functional reserve. In contrast, this reserve is suppressed in similarly long-term macroalbuminuric and hypertensive patients with overt nephropathy in spite of their remarkably maintained glomerular filtration rate. This opposite impairment supports the interpretation that glomerular hyperfiltration is a determining mechanism in human diabetic nephropathy. [Diabetologia (2000) 43: 227-230]

Keywords Type I diabetes, diabetic nephropathy, renal functional reserve, amino acid infusion, glomerular hyperfiltration.
One major and unexplained characteristic of Type I (insulin-dependent) diabetes mellitus is that all patients with good blood glucose control do not incur a similar risk of developing diabetic nephropathy

Received: 6 July 1999 and in revised form: 11 October 1999

Corresponding author: Dr. J.-L. Ader, Laboratoire d'Explorations Fonctionnelles Rénales et Métaboliques, Hôpital de Rangueil, 1, Avenue Jean Poulhès, F-31043 Toulouse Cedex 4, France

Abbreviations: GFR, Glomerular filtration rate; RFR, renal functional reserve; ERPF, effective renal plasma flow; RVR, renal vascular resistance; $\mathrm{DN}$, diabetic nephropathy; RBF, renal blood flow.
(DN). Even if glomerular injury is multifactorial, there is general agreement that the outbreak of glomerular scarring imposes an additional mechanical burden on the intact glomeruli by elevating the single nephron glomerular filtration rate (GFR). Such a glomerular hyperfiltration completes a vicious circle and could be determining in the process of relentless parenchymal destruction and functional decline $[1,2]$.

Renal functional reserve (RFR) is defined as the difference between basal GFR and GFR increased by stimuli such as oral protein load or amino acid infusion [3]. The reduction or the absence of functional reserve in renal diseases could imply that the residual nephrons are already in a state of permanent glomerular hyperfiltration [2]. Having previously observed 
that RFR was suppressed in patients with overt diabetic nephropathy [4], we designed the present study to examine whether patients with long-lasting Type I diabetes but exhibiting neither albuminuria nor hypertension are conversely characterized by an intact RFR.

\section{Subjects and methods}

Study subjects (Table 1). The study (previously approved by the ethics review board of Toulouse, France) was carried out in 20 long-term Type I diabetic patients and in 15 healthy control subjects.

Of the patients, ten with diabetes duration of 27 years were clinically free of the diabetic nephropathy (DN-). None of them was submitted to converting enzyme inhibitor therapy. The other ten patients had suffered diabetes for 24 years and were in the overt clinical stage of diabetic nephropathy (DN +) having developed macroalbuminuria and hypertension. All the DN + patients were usually maintained on stable doses of a converting enzyme inhibitor of which they were deprived for 1 week before the day of the study. All DN- and $\mathrm{DN}+$ patients had been trained with the same educational programme and were on intensified insulin therapy with either multiple daily injections (11 patients) or continous s.c. insulin infusion with an external pump ( 9 patients).

Control subjects were 15 normoalbuminuric and normotensive healthy volunteers who had given their informed consent.

Patients and control subjects followed an identical isocaloric diet ( $50 \%$ carbohydrates, 4 to $6 \mathrm{~g} \mathrm{NaCl}$ and $1.1 \mathrm{~g}$ per $\mathrm{kg}$ body weight protein daily content) at least 1 week before the studies.

Study protocol, determinations and calculations. Renal functional reserve studies were completed as previously described [4]. Continous s.c. insulin infusion was given with an external pump during the night and throughout the test to maintain the glycaemic level between 5.5 and $9.9 \mathrm{mmol} / \mathrm{l}$. We carried out eight successive 1-h inulin and $p$-amino hippurate clearance periods: two before, three during and three after (baseline, stimulation and recovery periods, respectively) an infusion of $7.4 \%$ amino acid solution (Azonutril 25 diluted v/v with sterilized distilled water, conveying approximately $4.5 \mathrm{mg}$ of a mixture of $20 \mathrm{~L}$-amino acids per min per $\mathrm{kg}$ body weight).

Glomerular filtration rate (GFR) and effective renal plasma flow (ERPF) were estimated from urinary clearances of inulin and $p$-amino hippurate, respectively. Renal functional reserve was equated with the difference between the higher GFR measured during amino acid infusion and baseline GFR. Renal blood flow (RBF) was calculated as the ratio of ERPF to 1-haematocrit, and renal vascular resistance (RVR) as the ratio of mean arterial pressure $\mathrm{mmHg}$ to $\mathrm{RBF}, 1 / \mathrm{min}$. All rates of filtration, flow and excretion as well as RVR are expressed per $1.73 \mathrm{~m}^{2}$ of body surface area, and fractional data as percentages.

Statistical analysis. The values reported represent means \pm SEM. The results were processed by repeated variance analysis measurements. Differences between values were analysed using the Scheffe $F$ test and the Mann-Whitney $U$ test. Results with $p<0.05$ were considered statistically significant. Analysis of covariance was used to further evaluate the relative importance of independent variables on the dependent variable RFR.
Table 1. Characteristics of patients with long-lasting Type I diabetes with $(\mathrm{DN}+)$ and without $(\mathrm{DN}-)$ diabetic nephropathy and of control subjects

\begin{tabular}{|c|c|c|c|}
\hline Characteristic & $\mathrm{DN}+$ & $\mathrm{DN}-$ & Control \\
\hline Age (years) & $41.9 \pm 3.6^{\mathrm{a}}$ & $44.9 \pm 3.0^{\mathrm{b}}$ & $31.4 \pm 2.3$ \\
\hline Duration of diabetes (years) & $24 \pm 3$ & $27 \pm 3$ & - \\
\hline Sex ratio (men/women) & $7 / 3$ & $8 / 2$ & $8 / 7$ \\
\hline $\mathrm{BMI}\left(\mathrm{kg} / \mathrm{m}^{2}\right)$ & $23.8 \pm 0.6$ & $22.4 \pm 0.6$ & $21.9 \pm 1.0$ \\
\hline Protein intake (g per day) & $81.5 \pm 7.1$ & $81.2 \pm 6.4$ & $79.7 \pm 10.8$ \\
\hline $\begin{array}{l}\text { Fasting plasma glucose } \\
(\mathrm{mmol} / \mathrm{l})\end{array}$ & $7.5 \pm 0.5$ & $6.7 \pm 0.4$ & $5.6 \pm 0.2$ \\
\hline Insulin dose (U per day) & $34.4 \pm 2.4$ & $39.7 \pm 2.6$ & - \\
\hline $\begin{array}{l}\text { Fasting plasma C peptide } \\
(\mathrm{ng} / \mathrm{ml})\end{array}$ & $<0.10$ & $<0.10$ & - \\
\hline Glycated $\mathrm{HbA}_{1 \mathrm{c}}(\%)$ & $9.2 \pm 0.2^{\mathrm{d}}$ & $7.8 \pm 0.3$ & - \\
\hline $\begin{array}{l}\text { Urinary albumin excretion } \\
\text { (mg/day) }\end{array}$ & $2993 \pm 864^{\mathrm{d}}$ & $13 \pm 3$ & $9 \pm 2$ \\
\hline $\begin{array}{l}\text { Mean arterial pressure } \\
(\mathrm{mmHg})\end{array}$ & $110 \pm 5^{\mathrm{c}, \mathrm{d}}$ & $91 \pm 4$ & $82 \pm 2$ \\
\hline Serum creatinine $(\mu \mathrm{mol} / \mathrm{l})$ & $125 \pm 11^{\mathrm{c}, \mathrm{e}}$ & $72 \pm 4$ & $74 \pm 4$ \\
\hline $\begin{array}{l}\text { Creatinine clearance } \\
\left(\mathrm{ml} \cdot \min ^{-1} \cdot\left(1.73 \mathrm{~m}^{2}\right)^{-1}\right)\end{array}$ & $103 \pm 8^{a}$ & $127 \pm 10$ & $135 \pm 6$ \\
\hline
\end{tabular}

Values are means \pm SEM

${ }^{\mathrm{a}} p<0.05,{ }^{\mathrm{b}} p<0.01,{ }^{\mathrm{c}} p<0.001$ vs control subjects

${ }^{\mathrm{d}} p<0.01,{ }^{\mathrm{e}} p<0.001$ vs DN- patients

\section{Results}

Baseline GFR in $\mathrm{DN}+$ patients $\left(79 \pm 7 \mathrm{ml} \cdot \mathrm{min}^{-1}\right.$. $\left.\left(1.73 \mathrm{~m}^{2}\right)^{-1}\right)$, but not in DN- patients $(106 \pm 8 \mathrm{ml}$. $\left.\min ^{-1} \cdot\left(1.73 \mathrm{~m}^{2}\right)^{-1}\right)$, was significantly lower $(p<0.01)$ than in control subjects $\left(112 \pm 3 \mathrm{ml} \cdot \mathrm{min}^{-1}\right.$. $\left(1.73 \mathrm{~m}^{2}\right)^{-1}$ ) (Fig. 1). None of the DN-patients had a supranormal basal GFR. Stimulated GFR values were significantly higher than respective baseline values $(p<0.001)$ in $\mathrm{DN}-$ patients $\left(135 \pm 10 \mathrm{ml} \cdot \mathrm{min}^{-1}\right.$. $\left.\left(1.73 \mathrm{~m}^{2}\right)^{-1}\right)$ and control subjects $\left(138 \pm 5 \mathrm{ml} \cdot \mathrm{min}^{-1}\right.$. $\left.\left(1.73 \mathrm{~m}^{2}\right)^{-1}\right)$ but not in DN + patients $(86 \pm 7 \mathrm{ml}$. $\left.\mathrm{min}^{-1} \cdot\left(1.73 \mathrm{~m}^{2}\right)^{-1}\right)$. Amino acid-induced alterations in GFR were fully reversible in all groups.

Renal functional reserve was similar in $\mathrm{DN}-$ patients $\left(28 \pm 5 \mathrm{ml} \cdot \mathrm{min}^{-1} \cdot\left(1.73 \mathrm{~m}^{2}\right)^{-1}\right)$ and control subjects $\left(25 \pm 3 \mathrm{ml} \cdot \mathrm{min}^{-1} \cdot\left(1.73 \mathrm{~m}^{2}\right)^{-1}\right)$ (Fig. 1). It was absent in DN + patients whose increase in GFR $\left(7 \pm 4 \mathrm{ml} \cdot \mathrm{min}^{-1} \cdot\left(1.73 \mathrm{~m}^{2}\right)^{-1}\right)$ was not significant. Renal functional reserve expressed as a percentage of respective baseline values represented only $12 \pm 4 \%$ in $\mathrm{DN}+$ patients, i.e. a significantly lower percentage $(p<0.05)$ than in $\mathrm{DN}$ - patients $(26 \pm 4 \%)$ and control subjects $(23 \pm 2 \%)$. Analysis of covariance showed that patients' RFR was not affected by age $(p<0.62)$, $\operatorname{sex}(p<0.45)$, diabetes duration $(p<0.73)$, daily insulin dosage $(p<0.19)$, urinary albumin excretion rate $(p<0.62)$ or by mean arterial pressure $(p<0.065)$. It was only affected by baseline GFR $(p<0.02)$ and above all, by a "group effect" $(p<0.003)$, i. e. the dis- 


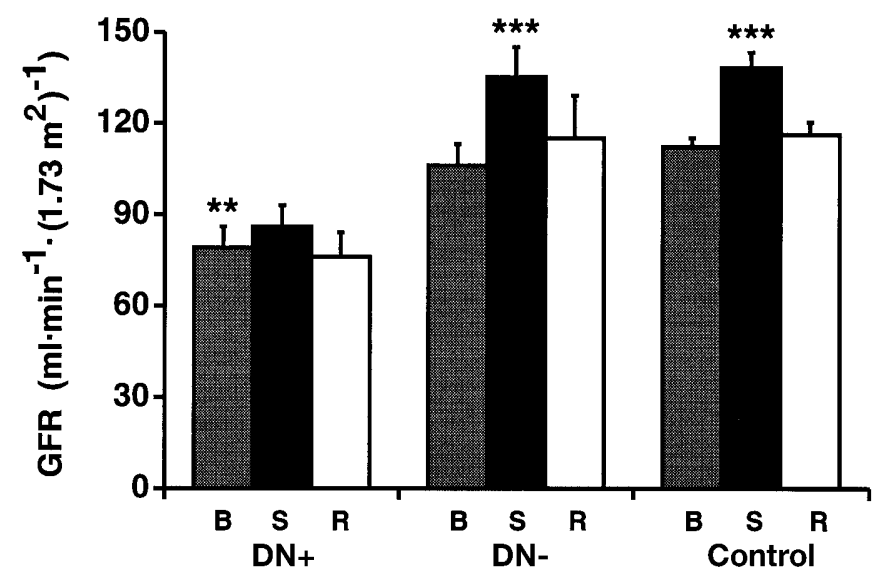

Fig. 1. Glomerular filtration rate (GFR) before (baseline, B), during (stimulation, $\mathrm{S}$ ) and after (recovery, R) amino acid infusion in 10 patients with diabetic nephropathy $(\mathrm{DN}+), 10$ patients without diabetic nephropathy (DN-) and 15 control subjects. Values are means \pm SEM. $* * p<0.01$ for differences with control subjects' baseline values. $* * * p<0.001$ for differences between stimulated and respective baseline values

tribution of patients according to the usual bioclinical criteria.

Calculated baseline RVR in $\mathrm{DN}+$ patients $\left(154 \pm 19 \mathrm{mmHg} / \mathrm{l} \cdot \mathrm{min}^{-1} \cdot\left(1.73 \mathrm{~m}^{2}\right)^{-1}\right)$, but not in DN- patients $\left(124 \pm 22 \mathrm{mmHg} / \mathrm{l} \cdot \mathrm{min}^{-1} \cdot\left(1.73 \mathrm{~m}^{2}\right)^{-1}\right)$, was significantly higher $(p<0.05)$ than in control subjects $\left(88 \pm 5 \mathrm{mmHg} / \mathrm{l} \cdot \mathrm{min}^{-1} \cdot\left(1.73 \mathrm{~m}^{2}\right)^{-1}\right)$. During stimulation, RVR decreased $(p<0.05)$ in both $\mathrm{DN}-$ patients and control subjects (by $13 \pm 4$ and $\left.8 \pm 3 \mathrm{mmHg} / \mathrm{l} \cdot \mathrm{min}^{-1} \cdot\left(1.73 \mathrm{~m}^{2}\right)^{-1}\right)$, respectively) but not in $\mathrm{DN}+$ patients.

\section{Discussion}

Previous RFR studies in long-term Type I diabetes have often been carried out in heterogeneous groups of patients at different stages of diabetic nephropathy and with dissimilar protein intakes. Our study compares the response to amino acid infusion only according to the presence or the absence of overt nephropathy in patients with Type I long-lasting diabetes. As far as possible, similar experimental conditions were created for patients and control subjects to prevent any influence on the results while meeting clinical requirements. Our observations provide evidence that the ability of the kidney to vasodilate and to retain a RFR is intact in normoalbuminuric normotensive patients whereas it is suppressed in macroalbuminuric hypertensive patients in spite of the similar long-term course of the disease. In addition, analysis of covariance clearly establishes that the major factor influencing renal reserve in our study is the stage of renal involvement as determined typically by the prevailing proteinuria and blood pressure.
We found that RFR was suppressed in DN + patients, thus confirming our previous results in another group of patients [4]. One important point is that serum creatinine concentration and creatinine clearance were almost normal and that true GFR, as evaluated by inulin clearance, was still considerably high approximating $80 \mathrm{ml} \cdot \mathrm{min}^{-1} \cdot\left(1.73 \mathrm{~m}^{2}\right)^{-1}$. Clearly, the baseline filtration process is remarkably maintained in spite of the irreversible glomerular functional impairment which is evidenced by the increased renal resistance, the suppressed ability to vasodilate and the absence of an RFR. Thus, invariability of amino acid-stimulated GFR and absence of a RFR appear to provide much more sensitive assessments of the functional renal damage in overt diabetic nephropathy than usual baseline evaluation. In these patients with subnormal serum creatinine concentrations and creatinine clearance, the risk of rapid worsening of renal function in conditions of external stress, such as hypovolaemia or infection, might be widely underestimated.

The loss of RFR probably implies that the residual nephrons are working at maximum capacity and are permanently in a state of glomerular hyperfiltration. This interpretation correlates with the previously reported large variation among individual glomeruli in the expression of advanced lesions of diabetic nephropathy [5]. Even when expressed as a percentage of baseline GFR, RFR in DN + patients averages only $12 \%$ and is statistically significantly lower than in $\mathrm{DN}$ - patients and control subjects. This decreased amino acid-induced change in GFR is absolutely necessary to justify the interpretation that haemodynamics is deranged in spared glomeruli [6]. Moreover, RVR was not decreased by amino acid infusion in $\mathrm{DN}+$ patients as it was in control subjects and DNpatients.

On the other hand, an intact renal reserve exists in DN- patients having nonetheless suffered diabetes for approximately 27 years. Their response to amino acid infusion was similar to that of control subjects; i.e. an approximately $28 \%$ increase in GFR and a statistically significant decrease in renal resistance. These results are in agreement with the observation that certain normoalbuminuric patients never develop any histological signs of glomerulopathy even after many years of diabetes [7-9]. Our results indicate that glomerular function and renal haemodynamics can be considered as normal in such long-standing diabetic patients.

Preservation of a renal reserve in a prolonged silent stage of renal involvement and suppression in overt nephropathy favour the interpretation of an important part played by glomerular hyperfiltration in the progression of renal damage and worsening of diabetic nephropathy [10]. Although the results of our study do not substantiate any causal relation, they clearly indicate that hyperfiltration is a characteristic 
feature of remaining nephrons in human diabetes with nephropathy.

We conclude that the ability of the kidneys to have an RFR and to vasodilate is fully retained in patients having suffered long-term Type I diabetes who have no bioclinical sign of nephropathy whereas it is suppressed in proteinuric hypertensive patients in spite of their remarkably maintained GFR. These results justify the interpretation that glomerular hyperfiltration is a determining mechanism in the progression of human diabetic nephropathy.

Acknowledgements. This study was supported by grants from the Paul Sabatier University and the National Institute for Health and Medical Research.

\section{References}

1. Hostetter TH, Rennke HG, Brenner BM (1982) The case for intrarenal hypertension in the initiation and progression of diabetic and other glomerulopathies. Am J Med 72: 375-380

2. Brenner BM, Meyer TW, Hostetter TH (1982) Dietary protein intake and the progessive nature of kidney disease: the role of hemodynamically mediated glomerular injury in the pathogenesis of progessive glomerular sclerosis in aging, renal ablation, and intrinsic renal disease. $\mathrm{N}$ Engl $\mathrm{J}$ Med 307: 652-659

3. Amiel C, Blanchet F, Friedlander G, Nitenberg A (1990) Renal functional reserve. Nephrol Dial Transplant 5: 763-770

4. Sackmann H, Tran-Van T, Tack I, Hanaire-Broutin H, Tauber JP, Ader JL (1998) Renal functional reserve in insulindependent diabetic patients. Diabetologia 41: 86-93

5. Osterby R, Gundersen HJG, Nyberg G, Aurell M (1987) Advanced diabetic glomerulopathy. Quantitative structural characterization of non-occluded glomeruli. Diabetes 36: 612-619

6. terWee PM, Donker AJM (1994) Pharmacologic manipulation of glomerular function. Kidney Int 45: 417-424

7. Steffes MW, Bilous RW, Sutherland DER, Mauer SM (1992) Cell and matrix components of the glomerular mesangium in type 1 diabetes. Diabetes 41: 679-684

8. Osterby R (1992) Glomerular structural changes in Type I (insulin-dependent) diabetes mellitus: causes, consequences and prevention. Diabetologia 35: 803-812

9. Walker JD, Close CF, Jones SL et al. (1992) Glomerular structure in type 1 (insulin- dependent) diabetic patients with normo- and microalbuminuria. Kidney Int 41: 741-748

10. Zatz R (1996) Haemodynamically mediated glomerular injury: the end of a 15-year-old controversy? Curr Opin Nephrol Hypertens 5: 468-475 